\title{
The effect of siderosis
}

\section{and ascorbic acid depletion on bone metabolism, with special reference to osteoporosis in the Bantu}

\author{
By A. A. WAPNICK, S. R. LYNCH, H. C. SEFTEL, \\ R. W. CHARLTON AND T. H. BOTHWELL \\ South African MRC Iron and Red Cell Metabolism Unit \\ Department of Medicine, University of the Witwatersrand, \\ Fohannesburg, South Africa \\ AND JENIFER JOWSEY \\ Section of Surgical Research (Orthopedics), Mayo Clinic, \\ and Mayo Foundation, Rochester, Minnesota, USA \\ (Received I9 June I970-Accepted I6 September I970)
}

\begin{abstract}
I. There is an association between iron overload, ascorbic acid deficiency and osteoporosis in middle-aged South African Bantu males. The iron overload contributes to the ascorbic acid deficiency by accelerating its oxidative catabolism. The object of the present investigation was to explore the possibility that the osteoporosis results from chronic ascorbic acid deficiency.

2. On quantitative microradiography, percentage bone-formation surface was normal but percentage bone-resorption surface was significantly increased in ten osteoporotic subjects compared with seven control subjects.

3. There was a significant inverse correlation between bone mineral density and liver storage iron concentration in thirty-five Bantu subjects. In thirteen individuals aged 39 years or less, liver storage iron concentration was significantly correlated with percentage bone-resorption surface.

4. Guinea-pigs deprived of ascorbic acid for $2 \mathrm{I} \mathrm{d}$ exhibited both significantly diminished percentage bone-formation surface and increased percentage bone-resorption surface.

5. Guinea-pigs overloaded with iron by injections of iron dextran developed significantly reduced hepatic ascorbic acid concentrations and bone mineral densities; percentage boneformation surface was significantly diminished and percentage bone-resorption surface significantly increased. Ascorbic acid injection largely prevented the bone changes.
\end{abstract}

Severe and disabling osteoporosis is not uncommon in middle-aged Bantu males in Johannesburg (Grusin \& Samuel, 1957; Seftel, Malkin, Schmaman, Abrahams, Lynch, Charlton \& Bothwell, I966; Lynch, Berelowitz, Seftel, Miller, Krawitz, Charlton \& Bothwell, 1967). It is usually associated with two other conditions: severe siderosis and depleted tissue ascorbic acid stores. Frank clinical scurvy is not infrequently present. The iron overload in this population develops as a consequence of the presence in the diet of large quantities of inorganic iron. The major source of this is the vessels used for the fermentation of the traditional alcoholic drinks, large quantities of which are consumed by most adult males (Walker \& Arvidsson, I953; Bothwell, Seftel, Jacobs, Torrance \& Baumslag, 1964). In one necropsy study as many as $20 \%$ of adult male hospital patients had hepatic storage iron concentrations in the range found in idiopathic haemochromatosis (Bothwell, Charlton \& Seftel, 1965). 
Evidence has been obtained that the iron overload plays an important part in the development of ascorbic acid deficiency. It has been shown that oxidation products of ascorbic acid are excreted when the vitamin is injected, and it has been concluded that accelerated oxidative catabolism due to the presence of large deposits of ferric iron contributes to the depletion of tissue ascorbic acid (Seftel et al. 1966; Lynch, Seftel, Torrance, Charlton \& Bothwell, 1967; Wapnick, Lynch, Krawitz, Seftel, Charlton \& Bothwell, r968). The contribution of iron overload to the pathogenesis of scurvy in this population is emphasized by the fact that neither condition occurs in the children, even though the ascorbic acid content of the diet is low and other deficiency diseases are common (Trowell, 1960).

Several possible reasons for the development of osteoporosis in these individuals have been considered in previous studies. As yet, however, convincing evidence has not been obtained that protein deficiency, hepatic or endocrine disease or calcium deficiency is responsible (Seftel et al. 1966; Lynch, Wapnick, Seftel, Charlton \& Bothwell, 1970). Scurvy has been stated to cause osteoporosis in experimental animals (Höjer, I923; Bourne, 1943-4) and in children (Park, Guild, Jackson \& Bond, I935; Bourne, 1942), although it does not seem to have been reported in adults. It nevertheless seemed reasonable to postulate that chronic tissue ascorbic acid deficiency might lead to osteoporosis in siderotic Bantu subjects. Some evidence supporting this hypothesis has been obtained. In a study of asymptomatic manual labourers, $15 \%$ were found to exhibit radiological evidence of vertebral osteoporosis, and the mean leucocyte ascorbic acid concentration in these individuals was significantly lower than that in the group as a whole (Lynch, Berelowitz et al. 1967). The purpose of the investigation now described was to explore further the possibility that osteoporosis in the Bantu develops as a consequence of ascorbic acid deficiency.

\section{EXPERIMEN T AL}

\section{Investigations in human subjects}

Bone-formation surface and bone-resorption surface in Bantu subjects with osteoporosis. Ten patients aged between 33 and 59 years (mean $46 \cdot 7, \mathrm{sD} \pm 7 \cdot 5$ ) were studied. All showed the typical features of osteoporosis as it presents in the Bantu (Seftel et al. I966). Radiological evidence of vertebral collapse was present in all subjects. While in hospital the patients were given a diet similar to that to which they were accustomed, consisting essentially of meat, cooked vegetables and maize porridge. Fresh fruit was excluded. All patients were fully ambulant. Shortly after admission, a specimen of bone (approximately $0.5 \mathrm{~g}$ ) was excised under local anaesthesia from the iliac crest between 2.5 and $5 \mathrm{~cm}$ behind the anterior iliac spine. The bone samples were stored in ethanol and later prepared for quantitative microradiography.

Control specimens of iliac crest bone were obtained from seven non-siderotic male Bantu subjects who had died from severe trauma. The mean age, with standard deviation, of the subjects was $44^{\circ} \circ$ years $\pm 5^{\circ} 5$.

Relationship of bone mineral density, bone-formation surface, and bone-resorption surface to liver storage iron concentration. Thirty-five subjects, all of whom had died of 
trauma, were studied. None of them had been ill or confined to bed for more than $24 \mathrm{~h}$ before death. Their ages ranged from about 20 to 55 years. It was, however, not possible to ascertain the precise age of some subjects, since many Bantu do not know their exact date of birth. In such instances the estimate of the attendant pathologist was used. In each individual two specimens of bone were obtained from the left iliac crest between 2.5 and $5 \mathrm{~cm}$ behind the anterior superior spine. A Sacker's trephine, as modified by Williams \& Nicholson ( 1963 ), was used, and the technique described by Saville (1965) as modified by Lynch, Berelowitz et al. (1967) was followed. These specimens were used to evaluate mineral density. In addition, a wedge of bone was removed from the same area and preserved in ethanol for quantitative microradiographic studies, while a specimen of liver was taken for determination of the storage iron concentration.

\section{Investigations in guinea-pigs}

Effect of ascorbic acid depletion on bone mineral density, bone-formation surface, and bone-resorption surface. Forty male guinea-pigs weighing between 500 and $600 \mathrm{~g}$ were fed on a diet consisting of ascorbic acid-free guinea-pig production pellets (Delmas Milling Co., Randfontein, Transvaal, South Africa) and hay dried and heated at $43^{\circ}$ for $2 \mathrm{~h}$. The drinking water contained a supplement of ascorbic acid ( $140 \mathrm{mg} / \mathrm{l}$ ). The calcium intake of a guinea-pig on this diet is approximately $8.4 \mathrm{mg} / \mathrm{d}$. After a week on the diet the animals were randomly divided into a control group and three experimental groups. The control group continued to receive the original diet, but ascorbic acid was withdrawn from the drinking water of the three experimental groups. After r $4 \mathrm{~d}$ the animals in the first of these three groups were killed. At this time ascorbic acid was restored to the drinking water of the second group, while the last group continued to receive no ascorbic acid. After a further $7 \mathrm{~d}$ the control group and the remaining two experimental groups were killed. About I $g$ liver was imm diately removed for determination of the ascorbic acid concentration, and the tibias and femurs were dissected free of surrounding tissue. The mineral density of the tibias was determined, and the femurs were submitted to quantitative microradiography.

Effect of iron overload on tissue ascorbic acid stores and bone mineral density, boneformation surface and bone-resorption surface. Twenty-three male guinea-pigs weighing between 600 and $65^{\circ} \mathrm{g}$ were fed on the standard ascorbic acid-free guinea-pig diet, together with ascorbic acid-supplemented drinking water (140 mg/l). This was continued throughout the experiment. The animals were randomly assigned to three groups. The control group (nine animals) received injections three times a week into the thigh muscle of $\mathrm{I} \mathrm{ml} 6 \%(\mathrm{w} / \mathrm{v})$ dextran in $0.9 \% \mathrm{NaCl}$ solution. The second group (nine animals) and the third group (five animals) were injected with I ml Imferon (Iron Dextran injection BP; Fisons Pharmaceuticals Ltd, Loughborough, England) (50 mg iron) three times weekly. In addition, an intramuscular injection of $40 \mathrm{mg}$ ascorbic acid was given three times weekly to the third group. After 6 weeks the iron dextran injections were stopped (total iron dose $900 \mathrm{mg}$ ), but the third group of animals continued to receive injections of ascorbic acid. All the animals were maintained on the diet with ascorbic acid in the water for a further 26 weeks, during which 
time they were weighed twice weekly. They were then killed and the tibias and femurs removed for mineral density determinations and quantitative microradiography respectively. The ascorbic acid concentrations and the storage iron concentrations in the livers were also determined.

\section{Laboratory methods}

Liver ascorbic acid was measured by the method of Roe (1954) and the liver storage iron content by the method of Torrance \& Bothwell (1968). All bone specimens were immediately placed in $70 \%(\mathrm{v} / \mathrm{v})$ ethanol. Thereafter they were placed in $90 \%(\mathrm{v} / \mathrm{v})$ ethanol and finally in absolute ethanol. The specimens were allowed to stand for $24 \mathrm{~h}$ in the first two concentrations and were stored in the absolute ethanol before processing. Bone mineral density was determined from the estimation of the volume of the specimen by mercury displacement and the measurement of its ash weight (Lynch, Berelowitz et al. 1967). Bone-formation surface and bone-resorption surface were quantitated microradiographically by the method of Jowsey (I966).

\section{RESULTS}

\section{Investigations in human subjects}

Bone-formation surface and bone-resorption surface in Bantu males with osteoporosis. The percentage bone-formation surface varied widely in patients with clinical osteoporosis, but was not significantly different from that in the control group. The mean values and the standard deviations were $2 \cdot 9 \pm 3.3 \%$ and $2 \cdot 3 \pm 1 \cdot 4 \%$ respectively. In contrast, there was increased percentage bone-resorption surface in all the osteoporotic subjects, the mean value and standard deviation being $\mathrm{I}_{3} .4 \pm 3.9 \%$. In the control group this value was $6.9 \pm \mathrm{I} \cdot 8 \%$, and the difference between the groups was significant $(P<0.00 \mathrm{I})$.

Relationship of bone mineral density, bone-formation surface, and bone-resorption surface to liver storage iron concentration. There was a significant inverse correlation between bone mineral density and hepatic storage iron concentration $(r=-0.6 \mathrm{r}$, $P<0.001$ ). A negative exponential appeared to fit the values better than a straight line (Fig. I), and the correlation between the logarithm of the bone mineral density and the hepatic iron concentration was closer $(r=-0.89, P<0.00 x)$. Percentage bone-formation surface and percentage bone-resorption surface varied considerably, and no correlation with hepatic storage iron concentration could be discerned in the group as a whole. Since age affects not only both these measurements (Jowsey, I966) but also bone mineral density (Trotter, Broman \& Peterson, 1960; Arnold, r964; Mueller, Trias \& Ray, I966), the relationships were examined separately in the thirteen subjects aged 39 years or less and in the twenty-two aged 40 years or more.

In the younger group the bone mineral density of one individual with markedly increased hepatic non-haem iron concentration appeared to be anomalously high (in parentheses in Fig. I). After excluding this individual, the coefficient of correlation in the younger group $(r=-0.69)$ was not significantly different $(P>0.2)$ from that 
in the older subjects $(r=-0.83)$. Moreover, although the correlation of bone mineral density with age was significant $(r=-0.42, P<0.01)$, it was not as close as that with liver iron concentration. In contrast with the mineral density findings, there was a highly significant direct correlation between liver storage iron and percentage resorption surface in the younger group $(r=+0.83, P<0.001)$, but no correlation in the older subjects (Fig. 2). In neither age group was there a significant correlation with percentage formation surface.

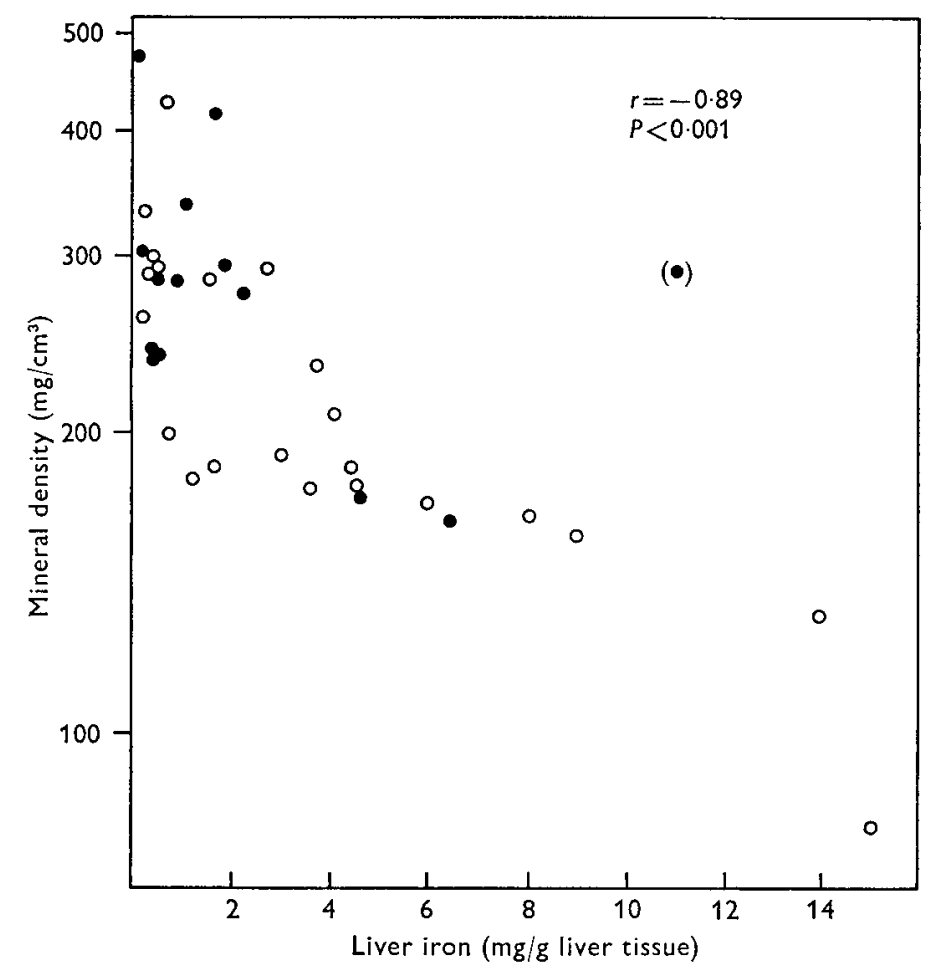

Fig. I. Relationship between the hepatic storage iron concentration and bone mineral density in adult Bantu males. 9 , aged under $4 \circ$ years; $O$, aged 40 years or more.

\section{Investigations in guinea-pigs}

Effect of ascorbic acid depletion on bone mineral density, bone-formation surface and bone-resorption surface (Table I). All the animals remained well during the experiment, but the group which received no ascorbic acid for $2 \mathrm{I} d$ did not gain as much weight as the control group $(P<0 \cdot 00 \mathrm{r})$. The weights of the animals in the remaining two groups were not significantly different from the controls. Hepatic ascorbic acid concentrations were very low in the two groups killed after $\mathrm{I} 4 \mathrm{and}$ 2I d respectively without ascorbic acid, while the concentrations in the control animals and those given ascorbic acid for the last $7 \mathrm{~d}$ of the experiment were similar. Bone mineral densities were similar in all groups. In the animals deprived of ascorbic acid for $2 \mathrm{I} d$, however, percentage formation surface was significantly decreased $(P<0.05)$ and percentage 
resorption surface significantly increased $(P<0.05)$. Percentage formation surface was also diminished in both the groups given no ascorbic acid for $\mathrm{I}_{4} \mathrm{~d}$ and the group to which ascorbic acid was restored after $14 \mathrm{~d}$ deprivation, but the differences from the value for the control group were not significant. Percentage bone-resorption surface in these two groups was not increased.

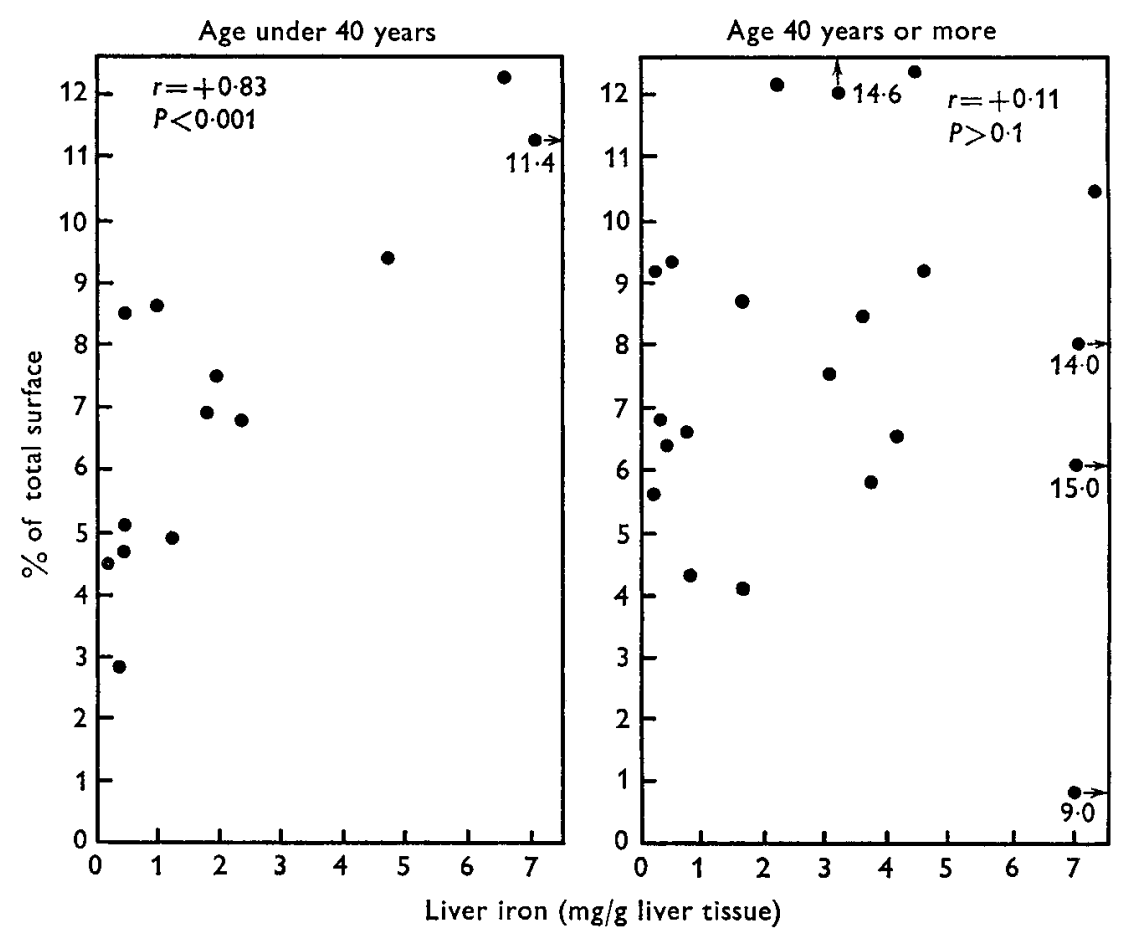

Fig. 2. Relationship between the hepatic storage iron concentration and the percentage bone-resorption surface in adult Bantu males.

Effect of iron overload on liver ascorbic acid concentration, bone mineral density, percentage bone-formation surface and percentage bone-resorption surface (Table 2). All the animals gained weight, and at the end of the experiment the three groups did not differ significantly in this respect. The mean hepatic ascorbic acid concentration in the guinea-pigs injected with iron dextran alone was, however, less than $3 \%$ of that in the other two groups $(P<0.001)$, which were not significantly different from each other. Mean liver-storage iron concentrations in the two groups which had received iron dextran injections were not significantly different from each other, although the value was somewhat lower in the animals which had also been given injections of ascorbic acid; both values were more than ten times as great as that in the control group $(P<0.001)$. In the animals given iron dextran only, bone mineral density was significantly lower than in the control group $(P<0.001)$, percentage formation surface was uniformly and significantly reduced $(P<0.02)$ and percentage resorption surface significantly increased $(P<0.00 \mathrm{I})$. In the animals given ascorbic acid injections as well as iron dextran, however, none of these values was significantly 
different from the control group, although mean bone density was somewhat diminished and mean percentage resorption surface slightly increased. Mean percentage formation surface was in fact greater than in the control group, but the range was wide.

\section{Table r. Effect of ascorbic acid depletion on bone metabolism in guinea-pigs}

(Ten animals per group)

\begin{tabular}{|c|c|c|c|c|}
\hline Measurement & $\begin{array}{c}\text { I } \\
\text { Controls }\end{array}$ & $\begin{array}{c}2 \\
\text { No ascorbic acid } \\
\text { for } 21 \mathrm{~d} \\
\text { before death }\end{array}$ & $\begin{array}{c}3 \\
\text { No ascorbic acid } \\
\text { for } 14 \mathrm{~d} \\
\text { before death }\end{array}$ & $\begin{array}{l}4 \\
\text { No ascorbic acid } \\
\text { for } 14 \mathrm{~d} \text {, } \\
\text { then ascorbic acid } \\
\text { restored for } 7 \mathrm{~d} \\
\text { before death }\end{array}$ \\
\hline Initial weight* $(\mathrm{g})$ & $560(27 \cdot 7)$ & $540(24 \cdot 8)$ & $550(29 \cdot 2)$ & $540(22 \cdot 9)$ \\
\hline Final weight* (g) & 7 II $(67 \cdot 0)$ & $582(49 \cdot 5)$ & $682(39.0)$ & $684(46 \cdot 5)$ \\
\hline $\begin{array}{l}\text { Liver ascorbic acid } \\
\text { concentration }(\mathrm{mg} / \mathrm{roo} \mathrm{g} \\
\text { wet weight)* }\end{array}$ & $12.9(4 \cdot T)$ & $0.8(0.5)$ & $I \cdot I(0.5)$ & $15.6(6.6)$ \\
\hline $\begin{array}{l}\text { Bone mineral density* } \\
\left(\mathrm{mg} / \mathrm{cm}^{3}\right)\end{array}$ & $6 r_{3}(27)$ & $620\left(5^{2}\right)$ & $638(3 r)$ & $634(23)$ \\
\hline $\begin{array}{l}\text { Percentage bone-forma- } \\
\text { tion surface } \dagger\end{array}$ & $9.2(5.8-15 \cdot 0)$ & $2 \cdot 8(x \cdot 2-4 \cdot 2)$ & $6 \cdot 2(4 \cdot 6-12 \cdot 0)$ & $6 \cdot 6(4 \cdot 6-10 \cdot 4)$ \\
\hline $\begin{array}{l}\text { Percentage bone-resorp- } \\
\text { tion surface } \dagger\end{array}$ & $18.6(17 \cdot 2-22 \cdot 6)$ & $26 \cdot 0(24 \cdot 6-29 \cdot 8)$ & $14 \cdot 6(12 \cdot 2-22 \cdot 2)$ & $16 \cdot 2(14 \cdot 6-21 \cdot 4)$ \\
\hline
\end{tabular}

Stastistical analyses were carried out in two ways. Where results were normally distributed (weight, liver ascorbic acid concentration and bone mineral density), the means and standard deviations are given, and Student's $t$ test was used for the analysis of the significance of differences. Since the results for boneformation surface and bone-resorption surface were not normally distributed, medians and interquartile ranges are given; the chi squared method was used for the analysis of the significance of differences. Only the following differences were significant. Weight (final): I v. $2(P<0.00 \mathrm{I}) ; 4$ v. $2(P<0.00 \mathrm{I})$; 3 v. $2(P<0.00 I)$. Liver ascorbic acid concentration: I v. $2(P<0.001) ;$ I $v .3(P<0.001) ; 4 v .2$ $(P<0.001) ; 4$ v. 3 (P<0.00I). Bone-formation surface: I $v .2(P<0.05) ; 4 v .2(P<0.05)$. Boneresorption surface: I v. $2(P<0.05) ; 4$ v. $2(P<0.05) ; 3$ v. $2(P<0.05)$.

* Means and standard deviations.

$\uparrow$ Medians and interquartile ranges.

\section{Table 2. Effect of iron overload on hepatic ascorbic acid concentration and on bone metabolism in guinea-pigs}

(Mean values and standard deviations for nine animals in group I, nine in group 2 and five in group 3 )

Measurement

Final weight $(\mathrm{g})$

Liver iron concentration ( $\mu \mathrm{g} / \mathrm{g}$ wet weight)

Liver ascorbic acid concentration $(\mathrm{mg} / \mathrm{I} 00 \mathrm{~g})$

Bone mineral density $\left(\mathrm{mg} / \mathrm{cm}^{3}\right)$

Percentage bone-formation surface

Percentage bone-resorption surface

\begin{tabular}{l}
\multicolumn{1}{c}{ I } \\
Controls \\
$723(84.7)$ \\
$308(156)$ \\
$29 \cdot 4(3 \cdot 1)$ \\
$731(28 \cdot 7)$ \\
$I \cdot 5(1 \cdot 5)$ \\
$I \cdot 3(0 \cdot 6)$
\end{tabular}

+ ascorbic acid supplement

$754(22 \cdot 2)$

$3645(1059 \cdot 7)$

$27.4(7 \cdot 5)$

$691(34 \cdot 4)$

$\mathrm{I} \cdot \mathrm{9}\left(3^{\circ} \mathrm{O}\right)$

$3.5(3.9)$

Student's $t$ test was used for the analysis of the significance of differences. Only the following differences were significant. Liver iron concentration: I v. $2\left(P<0^{\circ} \circ 01\right)$; I $v .3(P<0.001)$. Liver ascorbic acid concentration: I v. $2(P<0.001) ; 2$ v. $3(P<0.001)$. Bone mineral density: 1 v. $2(P<0.001)$. Bone-formation surface: I $v .2(P<0.02)$. Bone-resorption surface: I $v .2(P<0.001)$; 2 v. $3(P<$ 0.001 ). 


\section{DISCUSSION}

The classical concept of Albright \& Reifenstein (1948) ascribed the osteoporosis of scurvy to defective bone formation. It has been shown that ascorbic acid is needed for the synthesis of bone collagen (Höjer, 1923; Bourne, 1942-3; Gould, 1963), the maturation of the osteoblast (MacLean, Sheppard \& McHenry, 1939; Bourne, 1942-3; Gould, 1963) and the formation of osteoid (Dalldorf, 1938). Moreover, bone phosphatase activity is reduced in scurvy (Gould \& Shwachman, 194I-2; Follis, 195I), as is the uptake of calcium and phosphorus (Friberg \& Ringertz, 1954). If osteoporosis in the Bantu were due to ascorbic acid deficiency, it might therefore be expected that bone formation would be reduced in such subjects. In our study, however, percentage formation surface in Bantu patients with osteoporosis was not significantly different from control subjects, or from normal individuals of similar age studied previously (Jowsey, I966). In contrast, there was a significant increase in the percentage resorption surface in these patients. In this respect osteoporosis in the Bantu therefore resembles the common form of osteoporosis seen in other populations, which has a maximum incidence in postmenopausal women (Jowsey, 1966).

Although osteoporosis in the Bantu does not appear on this evidence to fit the classical concept of osteoporosis resulting from scurvy, the possibility that ascorbic acid deficiency is nevertheless the cause of the bone disease in these subjects is not excluded by these observations. In the experiment in which guinea-pigs were deprived of ascorbic acid for 2I d, the percentage resorption surface was significantly increased. The results suggest that ascorbic acid deficiency in guinea-pigs leads not only to diminished bone formation, but also to enhanced bone resorption. Theoretically, this could result from the formation of defective bone which is removed more rapidly than normal. The failure to demonstrate a reduced percentage formation surface in addition to increased resorption surface in the osteoporotic patients might possibly be due to the fact that values for percentage bone-formation surface are low even in normal adult subjects. Further evidence compatible with the view that severe ascorbic acid depletion may decrease bone formation and increase resorption in siderotic Bantu subjects has been provided by the findings in a parallel study in which various facets of calcium metabolism were investigated (Lynch et al. 1970). It was found that calcium absorption was relatively low, and that the urinary excretion of the mineral could be significantly reduced by administration of ascorbic acid. In addition, repletion with ascorbic acid increased the retention by bone of calcium administered intravenously.

In the short-term guinea-pig experiment significant alterations in percentage boneformation surface and percentage bone-resorption surface were observed only in the animals deprived of ascorbic acid for 2I d, and not in those killed after I4 d (Table I). The shortness of the period during which bone metabolism was affected before death presumably explains the failure to demonstrate decreased bone density in these animals. This experiment could possibly be criticized on the grounds that the animals deprived of ascorbic acid for 21 $\mathrm{d}$ did not gain as much weight as the controls. Some 
or all of the differences in bone metabolism might therefore have been due to different rates of growth rather than to ascorbic acid deficiency. This criticism does not, however, hold for the second guinea-pig experiment. In this long-term study there were no significant differences between the weights of the animals in the three groups at the conclusion of the experiment, and yet once again the mean percentage bone resorption surface in the guinea-pigs with low hepatic ascorbic acid concentrations was significantly greater than that in the control group, while formation surface was significantly decreased. The lower values for formation surface in this study, as compared with the short-term experiment, can be ascribed to the fact that the animals had. completed their growth when they were killed.

Other features of this experiment merit comment. It was noteworthy that osteoporosis and ascorbic acid deficiency developed in spite of the fact that the dietary intake of ascorbic acid was the same as that in the control group. The bone lesions and the vitamin deficiency must, therefore, be ascribed to the siderosis in the test animals, since this was the only variable. Evidence has been obtained in previous studies that iron overload contributes to ascorbic acid deficiency; the vitamin is irreversibly oxidized by the ferric iron in the storage compounds (Lynch, Seftel et al. 1967; Wapnick et al. I968). The observation that the bone abnormalities in siderotic animals were largely prevented by administering additional ascorbic acid suggests that they developed as an immediate consequence of the vitamin deficiency. While this experiment provides some support for the hypothesis that siderosis in the Bantu leads to osteoporosis by producing ascorbic acid deficiency, the fact that diminished percentage bone-formation surface was observed in the guinea-pigs but not in the Bantu subjects cannot be overlooked. Proof of the hypothesis will require the demonstration that the bone abnormalities in Bantu patients can be corrected by treatment with ascorbic acid alone.

It was unfortunately not possible to obtain valid hepatic ascorbic acid concentrations in the human necropsy study, because of the lapse of time after death. Correlations could, therefore, only be made between the hepatic iron concentrations and the various bone measurements. The previous observation (Lynch, Berelowitz et al. I967) that the concentration of storage iron in the liver is negatively correlated with bone mineral density was confirmed. The statistical analysis suggested that the correlation was a real one and not merely the result of the influence of age on each of the variables. The results were found to fit an exponential relationship more closely than a direct one (Fig. I), bone mineral density diminishing by about $5 \%$ for each $\mathrm{mg} / \mathrm{g}$ increase in hepatic storage iron. At a concentration of $10 \mathrm{mg} / \mathrm{g}$, therefore, bone mineral density was approximately half normal. Hepatic storage iron concentration was not significantly correlated with percentage bone-resorption surface except in the subjects below 40 years in age. Although the high correlation in this group was due to only three points (Fig. 2), it seems reasonable to attach some weight to the association since these were the only three young subjects with markedly increased hepatic storage iron concentrations. The absence of a significant correlation in the older individuals may perhaps be partly due to the presence of senile osteoporosis in some individuals with normal or only moderately increased iron stores. 
This work was supported by grants from the National Institutes of Health, USA (AMO 4912-08) and (AMO-8658), the Atomic Energy Board, South Africa and the Wellcome Trust, United Kingdom. Assistance with the statistical analysis was kindly provided by Dr A. E. H. Bleksley.

\section{REFEREN CES}

Albright, F. \& Reifenstein, E. C. (1948). The Parathyroid Glands \& Metabolic Bone Disease. Baltimore: Williams and Wilkins.

Arnold, J. S. (1964). In Dynamic Studies of Metabolic Bone Disease p. 59 [O. H. Pearson and G. F. Joplin, editors]. Oxford: Blackwell.

Bothwell, T. H., Charlton, R. W. \& Seftel, H. C. (1965). S. Afr. med. F. 39, 892.

Bothwell, T. H., Seftel, H., Jacobs, P., Torrance, J. D. \& Baumslag, N. (I 964). Am. F. clin. Nutr. r4, 47.

Bourne, G. H. (1942). Lancet ii, 66r.

Bourne, G. (1942-3). F. Physiol., Lond. ror, 327.

Bourne, G. H. (1943-4). F. Physiol., Lond. 102, 3 19.

Dalldorf, G. (1938). $\mathcal{~}$. Am. med. Ass. III, 1376.

Follis, R. H. Jr (195I). Bull. fohns Hopkins Hosp. 89, 9.

Friberg, U. \& Ringertz, N. R. (1954). Expl Cell Res. 6, 527.

Gould, B. S. (1963). Int. Rev. Cytol. 15, 301.

Gould, B. S. \& Shwachman, H. (I94I-2). Am. F. Physiol. 135, 485.

Grusin, H. \& Samuel, E. (I957). Am. F. clin. Nutr. 5, 644.

Höjer, J. A. (1923). Acta paediat., Stockh. Suppl. no. 3, p. 48.

Jowsey, J. (I966). Am. F. Med. 40, 485 .

Lynch, S. R., Berelowitz, I., Seftel, H. C., Miller, G. B., Krawitz, P., Charlton, R. W. \& Bothwell, T. H. (1967). Am. F. clin. Nutr. 20, 799.

Lynch, S. R., Seftel, H. C., Torrance, J. D., Charlton, R. W. \& Bothwell, T. H. (r967). Am. F. clin. Nutr. 20, 64r.

Lynch, S. R., Wapnick, A. A., Seftel, H. C., Charlton, R. W. \& Bothwell, T. H. (r97o). S. Afr. F. med. Sci. 35, 45 .

MacLean, D. L., Sheppard, M. \& McHenry, E. W. (1939). Br. F. exp. Path. 20, 45 I.

Mueller, K. H., Trias, A. \& Ray, R. D. (r966). f. Bone ft Surg. 48 A, r40.

Park, E. A., Guild, H. G., Jackson, D. \& Bond, M. (1935). Archs Dis. Childh. 1o, 265.

Roe, J. H. (1954). In Methods of Biochemical Analysis Vol. I, p. I 5 [D. Glick, editor]. New York: Interscience.

Saville, P. D. (1965). F. Bone Ft Surg. 47 A, 492.

Seftel, H. C., Malkin, C., Schmaman, A., Abrahams, C., Lynch, S. R., Charlton, R. W. \& Bothwell, T. H. (I g66). Br. med. F. i, 642 .

Torrance, J. D. \& Bothwell, T. H. (1968). S. Afr. F. med. Sci. 33, 9.

Trotter, M., Broman, G. E. \& Peterson, R. R. (1960). F. Bone $\mathscr{f t}$ Surg. 42 A, 50.

Trowell, H. C. (1960). Non-Infective Disease in Africa. London: Edward Arnold.

Walker, A. R. P. \& Arvidsson, U. B. (r953). Trans. R. Soc. trop. Med. Hyg. 47, 536.

Wapnick, A. A., Lynch, S. R., Krawitz, P., Seftel, H. C., Charlton, R. W. \& Bothwell, T. H. (Ig68). Br. med. F. iii, 704 .

Williams, J. A. \& Nicholson, G. I. (1963). Lancet i, 1408. 